\title{
PRÁCTICAS SOCIALES CON RELACIÓN A LA MUERTE EN EL SIGLO XIX
}

\author{
Carlos de la Cruz Villanueva \\ carlosdelacruzvillanueva@gmail.com \\ Universidad Ricardo Palma
}

\section{RESUMEN}

La siguiente investigación pretende aproximarse brevemente a cierto tipo de costumbres mortuorias desarrolladas en el siglo XIX en la ciudad de Lima y como estas son parte de las expresiones mentales plasmadas en el panteón general de Lima, hoy museo cementerio Presbítero Matías Maestro. Este análisis preliminar es posible mediante la observación de diversos relatos o descripciones de viajeros extranjeros que estuvieron en el Perú en aquel tiempo. Gracias a estos relatos nos podemos acercar al amplio universo que constituyen las costumbres referidas a la muerte en el periodo que va desde fines del régimen virreinal y la instauración de la república en el siglo XIX. PalabRas ClaVe: Costumbres mortuorias, relaciones de viajeros, cementerio Presbítero Matías Maestro, viajeros extranjeros.

\section{SOCIAL PRACTICES IN RELATION TO DEATH IN THE NINETEENTH CENTURY}

\begin{abstract}
The following research intends to briefly approach a certain type of mortuary customs developed in the 19th century in the city of Lima and as these are part of the mental expressions embodied in the general pantheon of Lima, now a cemetery museum Presbyter Matías Maestro. This preliminary analysis is possible by observing various accounts or descriptions of foreign travelers who were in Peru at that time. Thanks to these accounts we can approach the wide universe that constitute the customs referred to death in the period that goes from the end of the colonial regime and the establishment of the republic in the nineteenth century.
\end{abstract}

KEYWORDS: Mortuary customs, travelers' descriptions, cemetery Priest Matthias Master, foreign travelers. 


\section{Ideas preliminares}

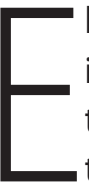
I tema referido a la muerte y sus actitudes mentales en el Perú fue uno de mis iniciales intereses de investigación histórica a inicios del siglo XXI, gracias a este tema pude comprender la importancia de la investigación en perspectiva temporal, también este interés sirvió de pretexto para ingresar al terreno del estudio de la historia de las mentalidades y de lo imaginario. Y fue través del tema de la muerte que pude acercarme tentativamente a comprender algunos alcances y limitaciones de estas formas de hacer historia.

Los años pasaron y el tema de la muerte siguió siendo algo de mi interés, pero ya no el más importante, pues otros temas fueron ingresando, como los monumentos, los personajes, la teoría y la metodología, y la vida de docente universitario me oriento por temas dirigidos a la enseñanza. Pero en los últimos meses la labor en la docencia en el curso de Formación Histórica del Perú provoco un reingreso a este tema, pero en su utilidad didáctica, pues a través de un proyecto de salidas pedagógicas, comúnmente conocidas como salidas de campo, generadas por el Programa de Estudios Básicos Universidad Ricardo Palma. Se seleccionó como uno de los lugares de visita al Museo Cementerio Presbítero Matías Maestro. Situación que género en mi una enorme emoción, por los recuerdos sobre una de mis primeras investigaciones ${ }^{1}$

Esta circunstancia hizo posible darle una nueva lectura respecto al tema de la muerte, los espacios públicos y las construcciones culturales y mentales, pero en esta oportunidad con el objetivo de divulgar e informar a la comunidad estudiantil universitaria mediante la salida pedagógica, logrando por este medio un acercamiento a nuestra historia material y mediante ella comprender a la sociedad en el tiempo.

\section{El Cementerio Presbítero Matías Maestro en el siglo XIX}

En las primeras dos décadas del siglo XIX el Perú vivió trascendentales procesos en su historia; el fin del virreinato, el desarrollo de la independencia peruana y con ello la formación inicial de la república peruana. Es el contexto en el cual se dará inicio y formación da la construcción de uno de los más importantes espacios públicos, que simbolizan el ingreso a la modernidad y la laicidad de la vida peruana del siglo XIX. Este espacio es el

1 Una primera investigación sobre el tema fue realizada en el curso de práctica preprofesional en Historia en el año 2002, curso a cargo de la historiadora Carlota Casalino Sen. El proyecto se enfocaba en la revalorización histórica del Museo Cementerio Presbítero Matías Maestro. Para el año 2005 la parte metodológica de la investigación sobre los cultos populares mortuorios en el Cementerio Presbítero Matías Maestro vio la luz en una charla expuesta en el COESCO organizado por la Universidad Nacional Federico Villarreal, que tuvo una primaria publicación en una revista estudiantil universitaria llamada Illapa en el año 2005, ya para el 2008 se constituyó en un artículo de investigación histórica que combinó lo metodológico con lo narrativo histórico referido a los cultos populares en el cementerio Presbítero Matías Maestro, fue publicada por la revista Aula y ciencia del Programa de Estudios Básicos de la Universidad Ricardo Palma. 


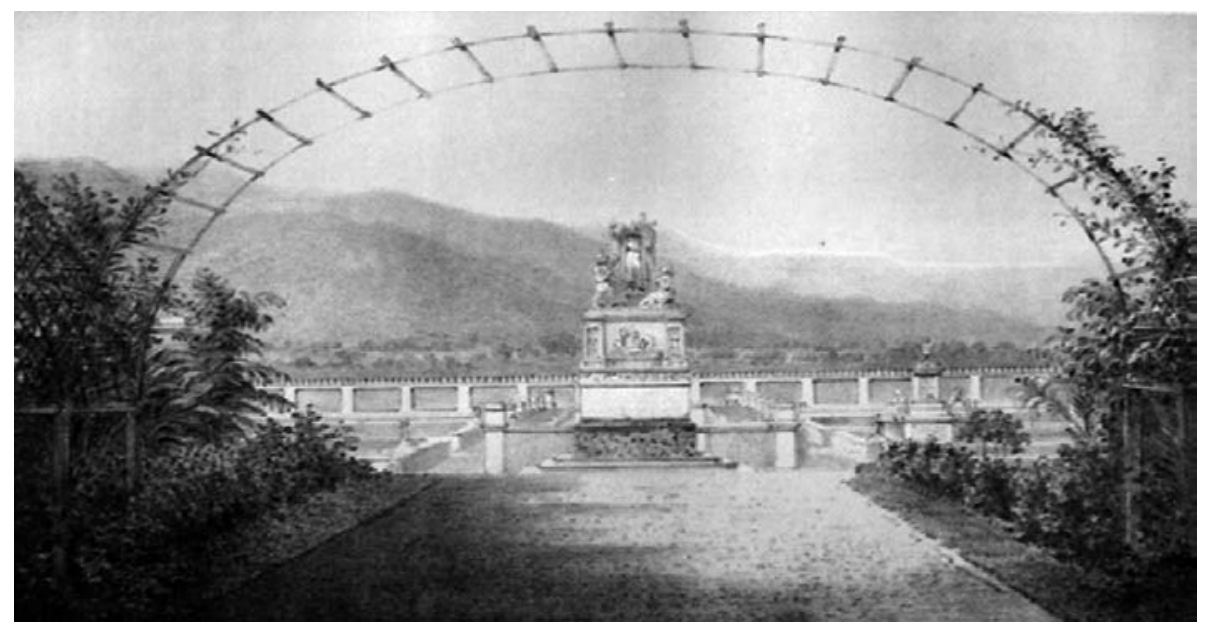

Imagen 1: Postal de la portada del Cementerio General de Lima de la segunda mitad del siglo XIX.

Vista 22/01/2015 http://www.limateca.org/timeline/vista-interior-del-cementerio-general

Cementerio General de Lima, en la actualidad el Museo Cementerio Presbítero Matías Maestro, una verdadera ciudad para los muertos de más de 20 hectáreas dedicadas al sepulcro de los muertos de la Lima decimonónica.

El campo santo es inaugurado en 1808, durante el periodo del virrey Abascal, tomando como nombre el de Panteón general de Lima y posteriormente el de cementerio general de Lima, el desarrollo de este espacio público en nuestra historia significó una renovación y adecuación en las costumbres funerarias y además de ser una de las principales reformas de salubridad de la época virreinal, cambiando la práctica social virreinal del Perú de enterrar a los muertos cerca a las iglesias, en los patios de las mismas, criptas, osarios subterráneos o tumbas en el interior de tierra consagrada por la fe. Practicas reservadas y restringidas para aquellos que podrían tener recursos económicos suficientes para solventar servicios o donaciones a los templos, dejando para los individuos que contaban con menos recursos o no con ellos, solo los entierros en lugares aislados, si eran nativos conversos o no conversos cercanos a huacas o cerros y a los pobres abandonaban los cadáveres a extramuros de la ciudad o cercanos a las iglesias, esperando a que las tendencias higienistas y las caritativas de la «piedad ilustrada» de la iglesia católica profesa, recoja los cadáveres para que sean depositados en fosas comunes.

Con el pasar de las décadas la costumbre de entierro saturaba las iglesias las cuales expedían el olor a muerte, situación que las autoridades virreinales tomarán en consideración y como parte de la solución a dicho dilema de las Reformas Borbónicas del siglo XVIII considerarían como parte de la solución el construir un panteón general a extramuros de la ciudad de Lima, para impedir o controlar algún tipo de enfermedades y modernizar la ciudad, para ello el diseño fue encargado al Presbítero Matías Maestro, el cual idealizo una ciudad para los muertos. En donde a través de la disposición arquitectónica del cementerio general a inicios del siglo XIX incorporara no solo una reforma 
de salubridad modernizadora, además trata de instaurar la idea «romper con la división social después de la muerte».

El cementerio en su traza original estaría constituido por cuarteles, con una zona central se colocaría una cúpula con un cristo yaciente simbolización de la muerte del cuerpo, que descansa en paz a la espera de salvación del alma y la promesa de la vida después de la muerte. Los cuarteles identificados con nombres de santos o sucesos de fe católica están compuestos por cuatro niveles que albergan a los nichos. Estos cuarteles componen amplios pasajes a manera de amplias calles como alamedas rodeadas por cipreses, sauces o arboledas que simbolicen un espacio para el descanso eterno. A su vez algunos de los cuarteles formarían estructuras cruciformes, pero en ningún lugar del diseño original se ven espacios para tumbas, criptas o mausoleos, guardando así el ideal de «igualdad de todos ante la muerte».

Dicho ideal se evidencia en la construcción del cementerio cuyo inicio no estaba reservado para la edificación de portentosas estructuras arquitectónicas dedicadas a honrar y recordar el descanso de un ser querido. La configuración del cementerio estaba diseñada para albergar a los muertos en cuarteles iguales para todos en donde lo único que los distinguiría sería la lápida, pero de aquel proyecto sólo queda en la actualidad el antiguo Cuartel de Resurrección ${ }^{2}$ que es tal vez uno de los únicos vestigios de dicho intento del siglo XIX que prevalece en la actualidad y es en donde se evidencian nichos de cuatro niveles uniformes en donde la única diferencia es la lápida y el material con el que está hecha. ${ }^{3}$ En la actualidad existen cerca de un centenar de cuarteles pero estos son muy diferentes a los iniciales, pero inspirados en los antiguos y que arquitectónicamente guardan otro fin, el cual es, el de estar reservados para los sectores medios de la sociedad del Perú del siglo XIX.

Con respecto a este ideal de igualdad sólo puedo agregar que con la llegada de la Independencia y la instauración de República Peruana, este intento al parecer no floreció, pues el cementerio pasa a ser administrado por la beneficencia compuesta por laicos los cuales alteran la traza original y van a convertir el campo santo en el reflejo de una demostración de poder de los sectores sociales a través de portentos monumentales y escultóricos, dejando nichos en los cuarteles para los sectores medios, tales como: mausoleos, criptas, tumbas, cenotafios entre otros los cuales son muestras claras de la jerárquica sociedad Limeña y provinciana que con la llegada de la república y el posterior crecimiento producto de un esplendor económico vivido por la llamada era del guano de la mano del desarrollo del laicismo y liberalismo en el Perú del siglo XIX se afirma y

2 Sobre la configuración antigua del cementerio y su proyección de la igualdad ante la muerte, es una investigación que está en elaboración en la actualidad.

3 Estas lápidas podían ser de metal, madera o mármol. Existía toda una resistencia, en un primer momento, por parte de la población para el uso de cementerios, pues la costumbre era sepultarlos en las iglesias, por considerar una mayor cercanía a Dios y la salvación, por ello los primeros pabellones no son muy concurridos, pero las normas higiénicas y la progresiva incorporación y adecuación de ideas laicas hicieron también la modernización de la visión de la vida a través de la muerte. 
materializa en el cementerio la diferenciación social que existía en vida y que prevalecería hasta en la muerte.

Es así que el Cementerio Presbítero en el siglo XIX se impone y se desarrolla la composición de un espacio público que desde sus inicios evidencia parte del proceso de modernización de la ciudad de Lima, con innovaciones correspondiente al período borbónico de mediados y finales del siglo XVIII, siendo concluido a inicios del XIX, conformándose así en uno de los proyectos más representativos de la estructura modernizadora ilustrada y modernas en el Perú4.

«El cementerio general de la ciudad de Lima» está ubicado en donde otrora se le consideraba extramuros de la ciudad de Lima en lo que hoy corresponde al distrito de Barrios Altos. Actualmente es uno de los monumentos históricos más importantes de la sociedad peruana de fines de la virreinal peruana y parte de nuestra vida republicana $\left(1808\right.$ y $\left.1956^{5}\right)$. Allí yacen los restos de hombres, mujeres de Lima y parte de provincia, extranjeros, gente de diversos cultos y creencias, marginados, párvulos y nacidos al morir (no natos), presidentes, músicos, literatos, arquitectos, científicos, entro otros que encontraron el descanso en este lugar. Este sitio histórico cuya importancia se constituye en la evidencia física de una sociedad en movimiento y en donde lo artístico, lo monumental traslucen la intrincada e imponente división de la sociedad hasta después de la muerte.

En este lugar en sus inicios estaba reservado exclusivamente para quien podía costear su descanso eterno, ya sea de manera perpetua o enfitéuticamente (por un tiempo determinado) en la actualidad es un espacio público histórico el cual es una veta importante para el desarrollo de investigaciones sociales.

\section{Las costumbres una fuente de investigación}

Es en este lugar donde podremos ver materializada muchas de las creencias o expresiones sociales con respecto a la muerte, pero también el espacio físico nos puede ayudar a comprender algunas actitudes mentales descritas por viajeros que van a observar las practicas u expresiones referidas a la muerte en donde se plasma las memorias mentales conocidas comúnmente como costumbres las cuales nos evidencian el cambio y las resistencias sociales.

El comprender una costumbre o costumbres es una labor complicada, pues el dotar de racionalidad las prácticas sociales nos pueden generar incomprensión. Pero para este articulo didáctico mencionare que las prácticas sociales se nos presentan a los investiga-

4 Tratamiento que le da Carlota Casalino Sen en su tesis: La muerte en Lima en el siglo XIX, una aproximación demográfica, social, política y cultural. Lima 1999.

5 Debo de agregar que la fecha de cierre es el año de 1956, y la creación de nuevos espacios como el cementerio El Ángel y otros que décadas en adelante se han ido agregando a la conformación territorial de diversos distritos de Lima, pero ello no excluye la creación de nuevos pabellones para niños y otras personas que han comprado espacios y que incluso en el año 2000 sus restos han sido agregados en el cementerio. 
dores como una actividad recurrente por la sociedad, es decir es una actitud periódica que desarrollan los individuos en singular o plural en la cual evidencia varios sentidos en los cuales nos muestran una acción social, que en primer lugar satisface una necesidad mediática y en segundo lugar la satisfacción a la necesidad, aproxima a lo deseado y con ello al encuadre o canon social. Además por lo general las costumbres no llaman mucho la atención de la sociedad que las reproducen, pues ya es considerada una situación común y cotidiana que se diluye o transforma en el tiempo.

Es el interés del observador foráneo o el investigador que ubica, describe, contrasta, interpreta y comprende una costumbre, a su vez entiende una situación que sobresale de lo cotidiano y que comprende que es parte de la cotidianeidad de la sociedad disímil a la suya. Esta observación revela la particularidad, originalidad o singularidad de la sociedad, a su vez el observador percibe que a través del estudio a las acciones cotidianas se puede aproximar al entendimiento de cambios u permanencias de nuestra historia del Perú. Y es en el siglo XIX gracias a las observaciones realizadas por los llamados «viajeros», extranjeros que la historiografía se enriquecerá. Pues ellos dejaran como testimonio de sus observaciones en sus informes, relatos o diarios en los que se plasma su recorrido en parte de nuestro Perú en el siglo XIX y en cuyas páginas se deja testimonio de la sociedad en la cual estuvieron de paso y que en mucho se distingue a las de los que son de origen.

Sus apreciaciones vertidas en sus informes ${ }^{6} \mathrm{y} / 0$ relatos satisfacían dos intereses; el comunicar a sus autoridades, si es que dependían de alguna, sobre las particularidades o situaciones de gran importancia que podrían encontrar en las tierras que visitaban. Pero también sus descripciones satisfacían y transmitían sus motivaciones personales. Estas fuentes, son en la actualidad una vena para la investigación histórica pues producto aquella mirada de otro observador en el tiempo, nos proyecta a nuestro tiempo diversas costumbres que desafiaban los convencionalismos de su sociedad de origen o simplemente hacían recordar a actitudes muy antiguas que se realizaron o dejaron de hacer en sus tierras.

\section{Los viajeros y sus relatos sobre costumbres mortuorias}

Es en el siglo XIX que surgen en forma puntual una serie de relatos de viajeros extranjeros; alemanes, norteamericanos, franceses e ingleses principalmente que llegan a nuestros país, producto del crecimiento comercial fruto de la Segunda Revolución Industrial y el Imperialismo, es a través de estos relatos que podemos apreciar múltiples situaciones, acontecimientos, anécdotas, relatos y costumbres que serán ya en nuestros días materia prima para comprender algunos aspectos de la sociedad en las cuales les tocó vivir. Entre

6 En esta investigación haré uso de algunas fuentes impresas de viajeros del XIX. Es a través de sus informes en los cuales se relatan sus experiencias e intereses en estas tierras, gracias a ellos podemos aproximarnos a la comprensión de la sociedad de aquellos tiempos, pero sobre todo comprender los rezagos o continuidades en lo referido a las prácticas sociales establecidas. 
las múltiples observaciones tenemos algunas referidas a la muerte en el siglo XIX.Y algunas de ellas serán motivos de estas líneas.

En su paso por Chorrillos, en 1822, el viajero francés Gabriel Lafond comenta que los indios del Perú que se encargan de la pesca son muchos unos aprovechados pues a los que tienen dinero o extranjeros les venden el pescado más caro que a los lugareños o los de su misma condición, pero esta actitud es por la vida intensa que tienen y los riesgos a los que están expuestos por el trabajo de la pesca, pues escucho la conversación entre dos de estos indios comerciantes que le decía el uno al otro sus desventuras en la última pesca y que además uno de sus hijos había muerto y que para enterrarlo necesitaba que le presten dinero por un tiempo para cubrir los gastos de su entierro ${ }^{7}$ así tenga que pagarle en mil por ciento de interés. Ello nos muestra la importancia del entierro y lo costoso que es costear un entierro en el campo santo, pero sobre todo el interés por satisfacer esa necesidad.

Otro de los relatos impactantes fue el del oficial británico en función Robert Proctor ${ }^{8}$ que entre 1823 al 24, en su recorrido por el Perú para informar a comerciantes, mineros, empresarios e inversionistas financieros británicos, redacta un informe de las características comerciales y las condiciones de comercio en nuestro país. En su relato brinda múltiples detalles sobre costumbres de diversos grupos sociales, entre ellos y referidos al tema, nos relata que las costumbres funerarias para los sectores elevados de la sociedad son ostentosas y con una gran religiosidad, con una gran procesión que va desde la casa a la iglesia, luego se lleva en una carroza fúnebre al féretro y se continua la procesión que en ocasiones es nocturna con antorchas y acompañada de lloronas, para después de una milla de recorrido depositarlo en el cementerio que como describe «despide un olor pestífero, pues los cadáveres se ponen a penas bajo la superficie del suelo», afirmación muy cierta, pues los cadáveres son depositados en tumbas al cual agregan cal y arena para su descomposición y es por ello el fétido olor y por ello la necesidad de tener al cementerio en campo abierto a extramuros de la ciudad. Y en cuanto a descripción sobre aquellas personas que no pueden costear el entierro o como el describe «gente baja» una actitud mortuoria nos revela una práctica muy lamentable, pero a la mirada del viajero es «repugnante», relata que aquellas personas de escasos recursos económicos dejaban en envoltorios colocados en las paredes de las calles de las iglesias, muchos de estos cadáveres sin tratar con cal y despedían olores muy desagradables, por lo general los envoltorios contenían a niños los cuales por esas fechas eran muy frecuentes como el relata, lo cual podríamos tomar como un indicador de una enorme mortalidad infantil en los primeros años de la republica peruana.

Pero no solo son los muros de las iglesias el lugar preferido para dejar cadáver por parte de los pobres de Lima. Mathison ${ }^{9}$ otro viajero británico en su extenso recorrido por la costa peruana en 1822, nos describirá también que los muros que protegen el cemen-

\footnotetext{
Véase el relato completo en: Colección Documental de la Independencia del Perú, T. XXVII, Vol. 2, Lima, 1971: 132-133. Véase el relato completo en: Colección Documental de la Independencia del Perú, T. XXVII, Vol. 2, Lima, 1971: 132-133. Véase el relato completo en: Colección Documental de la Independencia del Perú, T. XXVII, Vol. 1, Lima, 1971: 288.
} 
terio y los baluartes o restos de los muros de las murallas de Lima, despidiendo un aroma desagradable en donde se ven a diario los cadáveres en envoltorios de todos aquellos que no pueden solventar el pago de un entierro digno. Y esperan la labor de la beneficencia y las medidas ilustradas de sanidad, que recogerán los cadáveres para depositarlos en las fosas comunes o crematorias en donde el anonimato, el abandono y la marginalidad son parte de las prácticas cotidianas

A su vez nos comenta que todos los actos fúnebres tenían como respaldo sonoro el redoble de campanas que era muy ruidoso por los materiales de las campanas. Situación que con la llegada de San Martin, se restringió a solo tocar campanadas cinco veces por día, dicha disposición designada por Bernardo de Monteagudo se dejara de tomar en cuenta por el hecho de la cantidad de actividades religiosas y que demanda la sociedad como: bautizos, matrimonios, velorios entre otras.

Otra apreciación interesante es hecha por el médico y geólogo René P. Lesson ${ }^{10}$, que en su recorrido entre realizado en 1823 entre los territorios de Lima y Paita, nos comentara una costumbre que no es usual o ya no es frecuente por Francia. En su descripción personal nos aproxima a la variada composición orográfica de los territorios y sus características, además nos explica algunas de las enfermedades que son tratadas con prácticas herbolarias. Estas enfermedades causaron impacto en el Perú, como es el caso de la viruela, a su vez el incremento en la mortandad infantil producto del desconocimiento y alcance a la vacuna a la misma, pero también la falta de una cultura sanitaria y el descuido para niños en tierras. Como en Paita donde los niños son desaseados y con malas prácticas de salud, por ello la elevada mortandad de los infantes, que lo hicieron presenciar el velorio de un pequeño niño, en la cual los familiares preparan alimento en el velatorio celebran danzas y fiestas, pues el niño ha regresado a los cielos, pensamiento recurrente en estas tierras.

Otro viajero británico Alex Caldcleugh que en su estadía por Lima y en Callao en 1821 nos relata sus impresiones científicas y económicas sobre estas ciudades, preocupado por las relaciones económicas y el comercio en el Perú que se ve afectado en meses previos a la independencia y durante la proclama de la misma, él también nos describe una costumbre que le causa extrañeza y se vincula a las practicas mortuorias, esta es la existencia de una orden llamada la «Buena Muerte» ${ }^{11}$ que son un grupo de monjes que atienden a la gente en sus últimos momentos de vida, que a lomo de mula se trasladan de lugar en lugar donde se les requiera en Lima y el Callao, cuya la función es dar los santos sacramentos u atenciones a las personas previas al morir, esta orden depende mucho de limosnas y la caridad para poder seguir haciendo su labor, que no es desapercibida, pero comúnmente frecuente en la ciudad de Lima, pues son reconocidos en sus recorridos y su vestimenta compuesta por una sotana negra y una cruz roja sobre el brazo izquierdo

10 Véase el relato completo en: Colección Documental de la Independencia del Perú, T. XXVII, Vol. 2, Lima, 1971: 394-396.

11 Véase el relato completo en: Colección Documental de la Independencia del Perú, T. XXVII, Vol. 1, Lima, 1971: 181. Además con respecto a la orden véase la información histórica en línea: http://blog.pucp.edu.pe/blog/ juanluisorrego/2011/11/10/los-padres-de-la-buena-muerte-o-cruciferos-de-san-camilio/ 
y al parecer le causa extrañeza pues muchas costumbres religiosas que se reproducen en América distan a seguir en Europa.

Otra valoración que nos adentra a costumbres sobre la muerte es la que realiza Charles Wiener ${ }^{12}$ que en 1875 en su recorrido por el Perú, cercano a la ciudad de Trujillo observa una ritualización fúnebre, que es una suerte de procesión a un niño muerto de piel morena, el cual está colocado en la zona central con unas alitas asemejando que fuese un angelito, una situación que nos relata un ritual funerario que combina la fe católica y la pérdida de un ser querido a temprana edad.

Este ritual está compuesto de una procesión, combinada con danzas y festejo. Pues en el imaginario este cadáver de niño aún no ha alcanzado la razón y es por ello que es considerado un angelito por la inocencia que representa la pureza de su corta vida, libre de pecado que ingresaría en forma inmediata al reino de los cielos. Esta forma ritual frecuente en el siglo XIX con el tiempo fue quedando en desuso y solo hasta nuestros días, queda el vestigio de estos relatos, grabados, pinturas y fotografías post morten que nos muestran ello, pero que en la actualidad solo queda en frases cuando muere un párvulo o un no nato, es común escuchar «ha muerto un angelito».

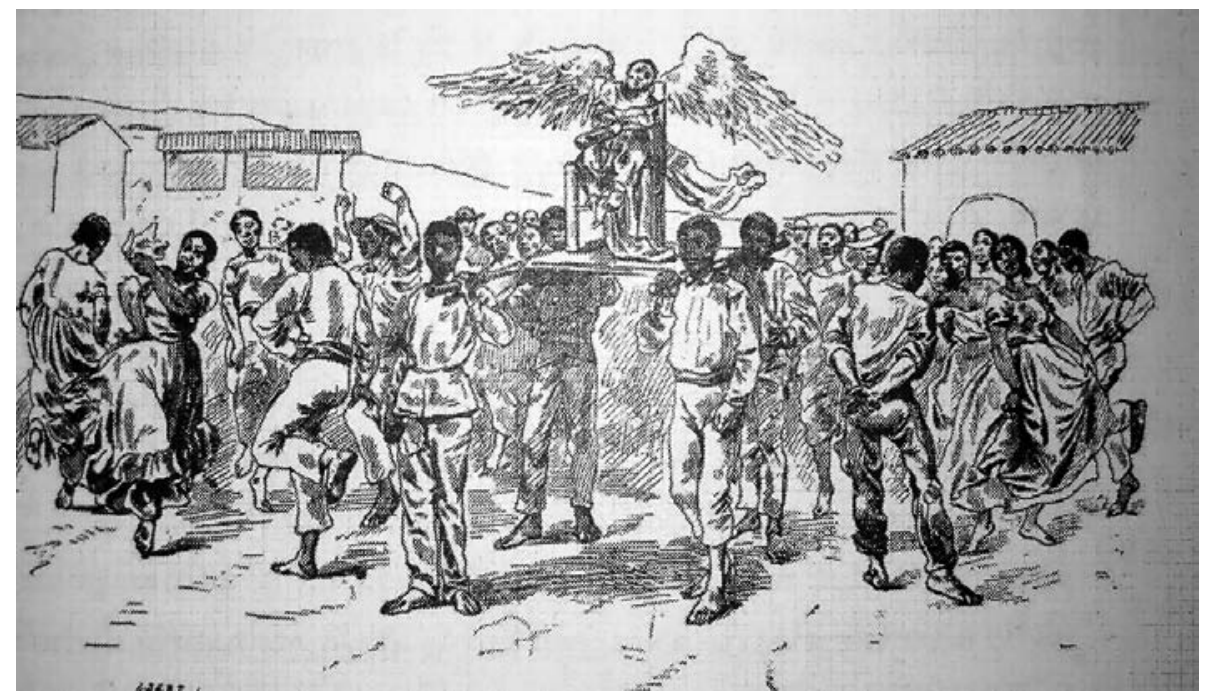

Imagen 2: Los funerales a un niño negrito Trujillo $1876^{13}$

Esta ritualización va de mano con la representación escultórica variada en el cementerio, pues es muy frecuente ver ya sea en tumbas, criptas o lapidas de niños como está representado el niño en un pesebre despertado por un ángel que lo llevara al reino de dios. Y sobre lo referente a lo de los «angelitos», décadas antes otro viajero británico, que

12 Véase el relato completo en: Wiener, Charles. Perú y Bolivia. Relato de un viaje. IFEA, Lima, 1993: 112.

13 Wiener, Charles. Perú y Bolivia. Relato de un viaje. IFEA, Lima, 1993. 
radicara en el Perú por su actividad comercial, es Heinrich Witt ${ }^{14}$ que en los primeros años del crecimiento económico producto del guano, nos relatara para 1842, que los velorios a los llamados «Angelitos «son muy frecuentes, pues el relata un velorio de un niño de tres años el cual la familia había colocado en la parte central de la habitación sobre una especie de altar, adornado con una vestimenta blanca y decorado con flores el niño era adornado para el deleite de todos los parientes y curiosos, esta ceremonia fúnebre era complementada con danzas y festejo pues «un angelito ha regresado al cielo»

Estas experiencias reproducen una suerte de vivencia sobre la muerte, que genera una reacción en las personas que van a reproducir la costumbre con fiel convicción sumergiéndola en la cotidianeidad.

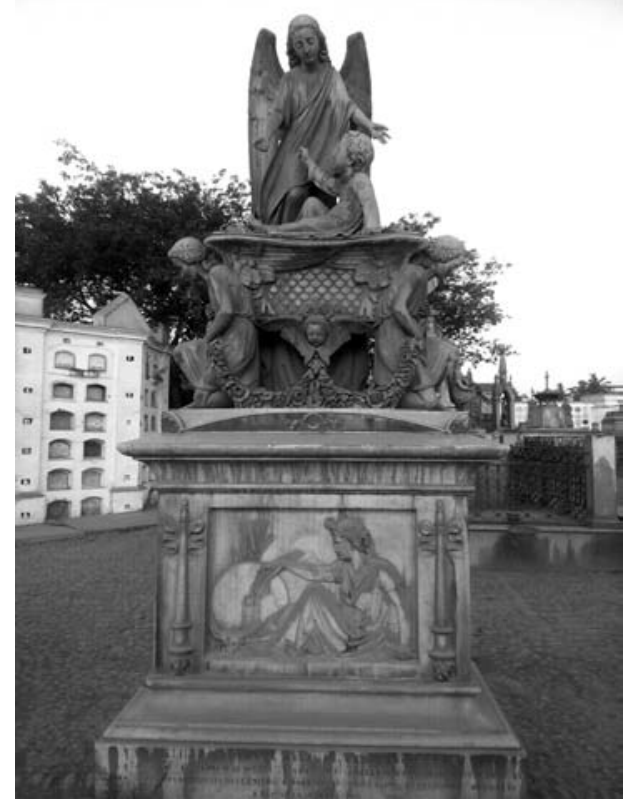

Imagen 3: Escultura sobre la tumba: representación de un niño en pesebre resucitando al llamado de un ángel. Archivo fotográfico personal de la tumba de María Minerva Rainuzo, de un año de nacida, fallecida en 1867.

Como idea final puedo agregar que son variadas las costumbres del Perú en el siglo XIX y en cuanto a lo referido al tema de la muerte una opinión brindan los viajeros, que a través de sus relatos nos ayudan a comprender la importancia de las costumbres y de los espacios públicos como cementerios que resguardan los rezagos de prácticas muy antiguas referidas a la muerte tal como se plasma en el pabellón Santa Bertha, conocido como el pabellón de los Suicidas, ubicado a la altura de la puerta 2 del cementerio Presbítero Matías Maestro.

Este pabellón a fines del siglo XIX e inicios del siglo XX, era concebido como parte del proyecto de expansión del cementerio, al parecer no cumple una función especifica, lo que suponemoses que cumple con alguna de las funciones originales del cementerio, es decir dentro de los planes del campo santo estaba provisto el ideal de reservar un espacio para la gente que atente en contra de su propia vida o la de otras vidas e incluso ateos o no creyentes católicos, que en la costumbre conservadora no puede lograr el descanso eterno. Es así que la beneficencia ubicara un espacio en el panteón general, para que estas almas encuentren el temporal descanso y más bien sea un territorio de meditación del alma o suerte de purgatorio simbólico.

14 Véase el relato completo en:Witt, Heinrich. Diario 1824-1890. Un testimonio personal sobreel Perú del siglo XIX, T.I, Banco Mundial, Lima, 1992: 383. 


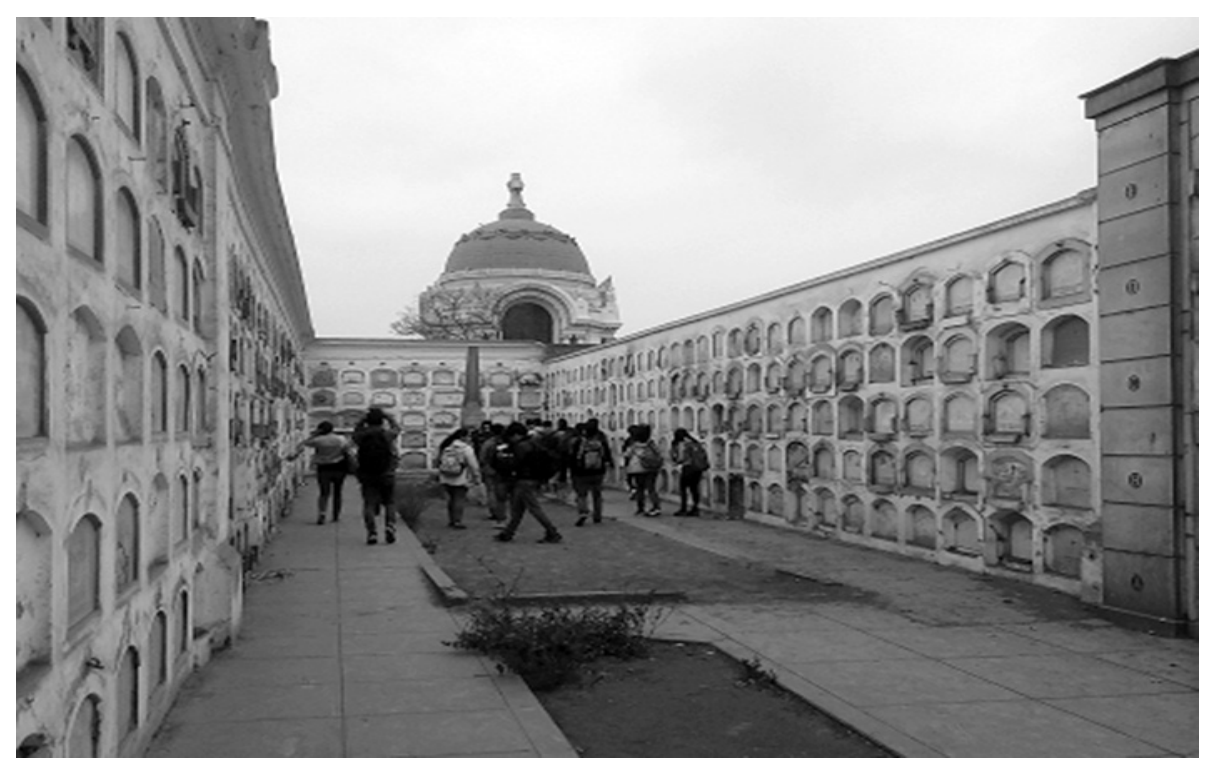

Imagen 4: Fotografía del pabellón de Santa Bertha, «Pabellón de los Suicidas» 21/09/2016. Archivo personal.

Pero hasta donde se ha podido investigar, el cementerio originalmente no tenía la intención de dedicar un lugar para estas personas, más bien ello corresponde a las ideas liberales y laicistas en el Perú de la segunda mitad del siglo XIX que tomarían en cuenta el desarrollo de un lugar simbólico de un purgatorio en un cementerio. Pero lo cierto es que el desarrollo del espacio se consolido en el tiempo, lo cual puede evidenciar el apego de la sociedad limeña tradicional del siglo XIX y de inicios del XX a las creencias religiosas cristianas y plasmó su actitud en la creación y desarrollo de este espacio dedicado para suicidas que hoy suscita la atención de un público motivado por este tipo de sucesos paranormales.

Este tipo de espacio también puede mostrarnos a través del grupo llamados los suicidas como la sociedad margina o trata a aquellos grupos sociales que salen de lo común, primero los identifica y los excluyen, pues en las partes más distantes del cementerio, al igual que en la sociedad, dirigen a estos grupos «peligrosos» lo más alejado a la capilla o el centro, en la misma orientación los chinos y los negros o los libertos, los culí15 o cualquier otro marginado por la sociedad, que a través del tiempo se ha desarrollado. Ya en el siglo XX es más frecuente la movilidad social, pero incluso en este lugar se puede visualizar la jerarquía social y la exclusión social y cómo se va transformando en el tiempo. Pero este

15 Apelativo utilizado para designar a los cargadores y trabajadores contratados con escasa calificación de la India, China y otros países asiáticos. También se utilizó para nombrar a los emigrantes de esos países que eran contratados en las colonias británicas, francesas y holandesas. La utilización de culíes o peones aumentó tras la abolición del comercio de esclavos. La vida de los culí consistía en sus contratos, los contratos con jornaleros indios establecían un periodo de trabajo de cinco años, a cambio del transporte y un sueldo. Pasados los cinco años el trabajador podía regresar a su hogar o buscar otro trabajo. Los culíes ofrecían sus servicios sobre todo en las colonias británicas, durante el siglo XIX e incluso el siglo XX. 
pabellón especial, casi abandonado en la actualidad, en el que se realizan rituales folclóricos prohibidos y en horas de la noche a ocultas de las autoridades del museo cementerio, este pabellón donde se rumorea que siempre se oyen lamentos y la gente acude para buscar algún aparecido, es un espacio físico en que se depositan historias de la violenta vida de la ciudad de Lima de finales del siglo XIX y del XX.

Sobre este espacio no hay un comentario en las relaciones de viajeros, lo que sabemos es producto del periodismo de la época. Es así que este pabellón se convierte en un lugar también de las historias reales pero que son explotadas como atractivo turístico utilizado por guías que se basan en informaciones de revistas para explicar casos de muertes como el caso de «... el amor suicida (...), las tumbas contiguas de María Subiría Briceño y Alejandrino Aparicio Subiría, dos primos hermanos, lo testimonian. La familia se opuso al matrimonio y su relación incestuosa solo para entregarnos una versión peruana de Romeo y Julieta: él se suicidó por amor el 12 de octubre de 1955, ella veintiún días después. Para aceptar el amor prohibido la familia tuvo que sufrir sus muertes.» ${ }^{16}$ Otro caso es el de Thompson un boticario que asesinó a su amante y luego se suicidó. Así hay una serie de casos pero los más sobresalientes son pocos, no son todos, aunque falta profundizar más en la investigación de los personajes. Un rastreo de las circunstancias de sus muertes darían con la respuesta para saber si este espacio es un lugar especial o es solo un mero atractivo turístico que se ha fortificado con el actuar de los grupos subalternos que buscan evidencias de almas en pena o de vida después de la muerte. Tal como plasma la revista Caretas al respecto del pabellón suicida «... Lo concreto es que en medio de tanta muerte el amor es más que un fantasma y continúa granjeando rutas insospechadas para florecer. No se trata solo de José Carlos y Mariela o de amores antediluvianos, sino de la cercanía que existe entre Eros y Tánatos. Ya bien sabía Quevedo que el amor suele vencer a la parca. Y para que el tema quede latiendo al infinito, como estos amores inextinguibles, qué mejor que recurrir a sus palabras: «Su cuerpo dejará no su cuidado; / serán ceniza, mas tendrá sentido; / polvo serán, mas polvo enamorado» ${ }^{17}$.

\section{Fuentes}

Fuente Monumental

Museo Cementerio Presbítero Matías Maestro:

Pabellón de los suicidas, pabellón Santa Bertha, Altura de la puerta dos del Cementerio. Avenida de la Muerte, Calle Central. Puerta 4.

\footnotetext{
16 La información pertenece a la revista Caretas de 19 junio 2008, Edición 2032. Lima. También se puede ubicar en: http://www.caretas.com.pe/Main.asp?T=3082\&S=\&id=12\&idE=781\&idSTo=0\&idA=33493 


\section{Bibliografía}

ARIĖs, Philippe (1982). La muerte en occidente. España, Argos Vergara S. A.

BolA, Lucien. (1995). Entre el ángel y la bestia. Santiago de Chile, Ed Andrés Bello. CASALINO SEN, Carlota. (1999). La muerte en Lima en el siglo XIX, una aproximación demográfica, social, política y cultural. (Tesis) Lima, PUCP.

Comisión NACIONAL del SeSQuicentenario de LA IndePendencia del Perú (1971). Relaciones de viajeros T. XXVII, Vol. 1 - 4, Colección Documental de la Independencia del Perú. Lima. Ed. Jurídica. S. A.

De LA CRuz VILlanueva, Carlos Augusto (2002). Informe de investigación. Curso de práctica preprofesional en Historia. Lima, UNMSM.

De la Cruz Villanueva, Carlos Augusto (2005). «Dos cultos populares el Cementerio Presbítero Matías Maestro (Una aproximación metodológica)». Conferencia. Coloquio Interdisciplinario de Investigaciones Históricas (COESCO). Universidad Nacional Federico Villarreal. Lima.

De LA CRUz VillanueVa, Carlos Augusto. Relaciones entre la vida y la muerte. Los cultos populares mortuorios en el cementerio presbítero Matías Maestro en el siglo XXI. Aula y Ciencia, año 2, \#1, Lima. PEB - URP

NúNEEZ, Estuardo (2013). Viajes y viajeros extranjeros por el Perú. Apuntes documentales con algunos desarrollos histórico-biográficos. Lima, URP.

LECOUTEUX, Claude (1999). Fantasmas y aparecidos en la edad media. España, Medievalia.

LEONARDINI, Nanda; David RodríGueZ y Virgilio F. CABANILLAS (Comp.) (2004). La imagen de la muerte. Primer Congreso Latinoamericano de Ciencias Sociales y Humanidades. Lima, UNMSM.

RODRíGUEZ, David y Limbergh HerReRA (Comp.) (2006). La imagen de la muerte. Segundo Congreso Latinoamericano de Ciencias Sociales y Humanidades. Lima, UNMSM - Editorial Línea Andina. WIENER, Charles (1993). Perú y Bolivia. Relato de un viaje. Lima. IFEA.

WITT, Heinrich (1992). Diario 1824-1890. Un testimonio personal sobre el Perú del siglo XIX, T.I - II, Lima. Banco Mundial. 